\title{
SARS-CoV-2 Induces Cytokine Responses in Human Basophils
}

\author{
Srinivasa Reddy Bonam ${ }^{1 \dagger}$, Camille Chauvin ${ }^{1,2+}$, Laurine Levillayer ${ }^{2+}$, \\ Mano Joseph Mathew ${ }^{3}$, Anavaj Sakuntabhai ${ }^{2,4}$ and Jagadeesh Bayry ${ }^{1,5 *}$ \\ 1 Institut National de la Santé et de la Recherche Médicale, Centre de Recherche des Cordeliers, Sorbonne Université, \\ Université de Paris, Paris, France, ${ }^{2}$ Functional Genetics of Infectious Diseases Unit, Department of Global Health, Institut \\ Pasteur, Paris, France, ${ }^{3}$ EFREI, Villejuif, France, ${ }^{4}$ Centre National de la Recherche Scientifique (CNRS), UMR2000, Paris, \\ France, ${ }^{5}$ Department of Biological Sciences \& Engineering, Indian Institute of Technology Palakkad, Palakkad, India
}

Basophils play a key role in the orientation of immune responses. Though the interaction of SARS-CoV-2 with various immune cells has been relatively well studied, the response of basophils to this pandemic virus is not characterized yet. In this study, we report that SARS-CoV-2 induces cytokine responses and in particular IL-13, in both resting and IL-3 primed basophils. The response was prominent under IL-3 primed condition. However, either SARS-CoV-2 or SARS-CoV-2-infected epithelial cells did not alter the expression of surface markers associated with the activation of basophils, such as CD69, CD13 and/or degranulation marker CD107a. We also validate that human basophils are not permissive to SARS-CoV-2 replication. Though increased expression of immune checkpoint molecule PD-L1 has been reported on the basophils from COVID-19 patients, we observed that SARS-CoV-2 does not induce PD-L1 on the basophils. Our data suggest that basophil cytokine responses to SARS-CoV-2 might help in reducing the inflammation and also to promote antibody responses to the virus.

Keywords: basophils, SARS-CoV-2, COVID-19, IL-3, Caco-2 cells, IL-13, IL-4, epithelial cells

\section{INTRODUCTION}

The current COVID-19 pandemic, caused by the new severe acute respiratory syndrome coronavirus 2 (SARS-CoV-2), presents an unprecedented danger to global health systems, with over 5.2 million confirmed fatalities $\left(10^{\text {th }}\right.$ December 2021) (1). Large number of studies have dissected the spectrum of innate and adaptive immune responses in COVID-19 patients and their role in the immunopathogenesis of the disease (2-7).

Basophils are rare immune cells. In addition to mediating the protection against helminth infection, basophils are well known for their role in the pathogenesis of various allergic inflammatory diseases of respiratory tract, gastro-intestinal tract and skin (8-10). A longitudinal systems-level analyses of immune cells from the blood indicates that basophils are depleted during acute and severe phases of COVID-19 (2) and in line with the established fact that basophils regulate $\mathrm{T}$ and $\mathrm{B}$ cell responses, a correlation between anti-RBD (receptor-binding domain) IgG titers and basophil number in the circulation has been observed (2). In addition, basophils also displayed an activated phenotype in COVID-19 patients (11). However, the direct response of human basophils to SARS-CoV-2 remains unexplored. 
In this study, we have investigated the response of human basophils to SARS-CoV-2 infection. We found that SARS-CoV-2 induces IL-4 and IL-13 cytokines both in resting and IL-3primed basophils without modifying the expression of surface markers including the checkpoint molecule PD-L1. In fact, PDL1 expression was at basal level. Our data indicate that activation of basophils by SARS-CoV-2 might support Th2 and antibody responses to the virus.

\section{MATERIALS AND METHODS}

\section{Reagents and Antibodies}

For flow cytometry, the following fluorochrome-conjugated monoclonal antibodies were used. BD Biosciences (Le Pont de Claix, France): CD13-APC (Clone: WM15), CD69-APC/Cy7 (Clone: FN50), CD274 (PD-L1)-FITC (Clone: MIH1); Miltenyi Biotec: FceRI $\alpha-P E$ (Clone: CRA-1); eBioscience (Paris, France): and fixable viability dye eFluor 506. Biolegend (Amsterdam, Netherlands): CD107a-BV421 (clone H4A3). IL-3 was from ImmunoTools (Friesoythe, Germany).

\section{Cell Lines}

Vero E6 (African green monkey kidney epithelial cells, ATCC, CRL-1586) was maintained in Dulbecco's modified Eagle's medium (DMEM) containing 10\% fetal bovine serum (FBS), $1 \%$ penicillin-streptomycin (PS) (5 units/mL penicillin, and $5 \mu \mathrm{g} /$ $\mathrm{mL}$ streptomycin). Caco-2 (Human colon epithelial cells, ATCC, HTB-37) was maintained in DMEM containing 20\% FBS, 1\% penicillin-streptomycin. All cell lines were cultured at $37^{\circ} \mathrm{C}$, $5 \% \mathrm{CO}_{2}$.

\section{Virus Strains}

The primary strain BetaCoV/France/IDF0372/2020 (EPI_ISL_410720 (GISAID ID); wild-type strain) was supplied by the National Reference Centre for Respiratory Viruses hosted by Institut Pasteur (Paris, France) and headed by Dr. Sylvie van der Werf, and the human sample was isolated and provided by Drs. Xavier Lescure, Yazdan Yazdanpanah from the Bichat Hospital, Paris.

\section{Virus Production}

Viral stocks were produced using Vero E6 in DMEM without FBS with a multiplicity of infection (MOI) $10^{-3}$ of the virus stock. After $1 \mathrm{~h}$ incubation at $37^{\circ} \mathrm{C}$ under $5 \% \mathrm{CO}_{2}$, all the medium used for infection was removed before adding fresh DMEM containing $2 \%$ FBS, $1 \%$ PS. Cells were incubated for further $72 \mathrm{~h}$ at $37^{\circ} \mathrm{C}, 5 \% \mathrm{CO}_{2}$.

\section{Virus Titration}

Viral titers were assessed by plaque assay in 24-well plates on Vero E6 cells $\left(1.5 \times 10^{5}\right.$ cells/well) in DMEM supplemented with $10 \%$ FBS and $1 \%$ penicillin-streptomycin. Ten-fold serial dilutions in DMEM without FBS and 1\% PS were used for the titration. After $1 \mathrm{~h}$ of incubation at $37^{\circ} \mathrm{C}, 5 \% \mathrm{CO}_{2}$, the medium was replaced by overlaying the cells with carboxymethyl cellulose
CMC/DMEM with $2 \% \mathrm{FBS}$ (vol/vol). After $72 \mathrm{~h}$ of incubation, the CMC/DMEM was removed and a mixture of crystal violet/ ethanol/formaldehyde was added for $30 \mathrm{~min}$ at room temperature. Experiments with live SARS-CoV-2 were performed according to Institut Pasteur guidelines for Biosafety Level 3 work.

\section{Purification of Basophils}

The buffy coats of the healthy donors (Centre Trinite, L'Établissement Français du Sang, Paris; EFS-INSERM ethical committee permission 18/EFS/041) were used to isolate peripheral blood mononuclear cells (PBMCs) by Ficoll density gradient centrifugation. Basophils were isolated from the PBMCs by negative selection using Basophil Isolation Kit II (Miltenyi Biotec, Paris, France).

\section{Basophil Infection}

Freshly isolated basophils were plated in a 96-well plate at a concentration of $0.1 \times 10^{6}$ cells $/ 100 \mu \mathrm{l} /$ well without FBS, and directly infected with the SARS-CoV-2 (primary strain IDF0372) at a MOI of one. Non-infected cells were used as a control. In some conditions, basophils were primed with IL-3 (20 $\mathrm{ng} / \mathrm{ml}$ ) along with infection. Vero E6 cells were used as a control of infection. After $1 \mathrm{~h}$, the medium was replaced by fresh $\mathrm{X}-\mathrm{Vivo}$ medium and the cells were further incubated for $24 \mathrm{~h}$ at $37^{\circ} \mathrm{C}, 5 \%$ $\mathrm{CO}_{2}$. After $24 \mathrm{~h}$ of culture, supernatants were collected and stored at $-80^{\circ} \mathrm{C}$ for subsequent cytokine quantification. The cells were processed for surface staining of various markers, such as FceR1, CD107a, CD13, CD69, and PD-L1. The cells were fixed with $4 \%$ paraformaldehyde and were acquired using LSR II (BD Biosciences). The data were analyzed by BD FACS DIVA and FlowJo software.

\section{Coculture of Basophils With Virus Infected Caco-2}

Human Caco-2 cells were plated a day before in 96-well plates. Cells were infected in DMEM without FBS with the SARS-CoV-2 primary strain IDF0372 at a MOI of one. After $1 \mathrm{~h}$, the medium was replaced by fresh DMEM medium containing 2\% FBS, $1 \%$ $\mathrm{PS}$ and cells were incubated at $37^{\circ} \mathrm{C}, 5 \% \mathrm{CO}_{2}$. After $24 \mathrm{~h}$, basophils $\left(0.1 \times 10^{6}\right.$ cells $/ 100 \mu \mathrm{l} /$ well $)$ were added on the top of infected Caco-2 $\left(5 \times 10^{4}\right.$ cells/100 $\mu \mathrm{l} /$ well $)$. The basophils were assessed for the expression of various surface markers after $24 \mathrm{~h}$.

\section{ELISA}

Cell culture supernatants were inactivated with Triton X-100 1\% $(\mathrm{v} / \mathrm{v})$ for $2 \mathrm{~h}$ at room temperature. The virus inactivated supernatants were analyzed for the cytokines, such as IL-13 and IL-4 (ELISA Ready-SET-Go, eBioscience).

\section{Statistical Analysis}

As highlighted in the figure legends, the experiments were repeated in several times by using cells from independent donors. Graphs and Statistical analyses were performed by the paired Wilcoxon test (for comparison between two groups) or one-way ANOVA Friedman test with Dunn's multiple 
comparisons post-test as indicated using Prism 8 (GraphPad Software Inc, CA). $\mathrm{P}<0.05$ was considered significant.

\section{RESULTS}

\section{SARS-CoV-2 Induces Limited Activation of Resting Human Basophils}

Basophils play a major role in the pathogenesis of various respiratory diseases (8-10). Though the phenotype of basophils was previously analyzed in COVID-19 patients (11), it was not clear whether the activated basophil phenotype observed in the COVID-19 patients was due to direct virus stimulation or a repercussion of inflammatory responses. Therefore, to address this question, we first evaluated the response of basophils to SARS-CoV-2 infection. In our study, we isolated basophils from the healthy donors' blood and were treated with SARS-CoV-2 for $1 \mathrm{~h}$ followed by $24 \mathrm{~h}$ incubation. The phenotype of basophils was analyzed by flow cytometry (Figure 1A). While the expression of CD13 and CD69 was not modified by SARS-CoV-2, a modest increase in the median fluorescence intensity of FcERI was observed on SARS-CoV-2-infected basophils (Figure 1B). SARS-CoV-2 had no cytopathic effects on the basophils as either cell yield or viability as analyzed by fixable-viable dye were not altered.

We analyzed whether SARS-CoV-2 infection induced cytokine responses in basophils. We found that both IL-4 and IL-13 cytokines were enhanced upon SARS-CoV-2 stimulation (Figure 1C) thus confirming SARS-CoV-2 induces activation of human basophils. These data together indicate that resting human basophils undergo limited activation by SARS-CoV-2. Our data also suggest that higher expression of activation markers reported on basophils from COVID-19 patients was possibly not due to the direct virus stimulation (11).

\section{SARS-CoV-2 Enhances Cytokine Production in IL-3 Primed Basophils}

Under certain conditions, basophils require prior priming to undergo activation by stimuli (12). We therefore investigated if SARS-CoV-2 could induce activation of basophils if they were primed. Data from various labs including ours have shown that among various cytokines, IL-3 induces strong priming of human basophils (12-15). Therefore, we primed the basophils with IL-3 along with SARS-CoV-2 stimulation. Priming with IL-3 enhanced the expression of various surface markers (compared to unstimulated basophils, Figure 1B) such as CD13 and CD69 (Figures 2A, B). However, SARS-CoV-2 did not alter the phenotype of IL-3-primed basophils (Figure 2B). Also, SARSCoV-2 did not induce degranulation of basophils as the expression of CD107a, a marker associated with basophil degranulation, was similar in both the experimental conditions. We confirmed that basophils either resting or IL-3-primed were not permissive to SARS-CoV-2 replication (Figure 2C).

Interestingly, SARS-CoV-2 significantly enhanced IL-4 and IL-13 cytokine production in IL-3 primed basophils (Figure 2D). Though significant, IL-4 enhancement was marginal compared to IL-13, which is not surprising as IL-4 induction in basophils is dependent on FceRI-mediated signaling (16).

\section{Lack of Basophil Activation by SARS-CoV-2 Infected Epithelial Cells}

The entry of SARS-CoV-2 into the cell depends on two receptors, angiotensin-converting enzyme 2 (ACE2) and type II transmembrane serine protease (TMPRSS2), which are involved in binding to RBD of the Spike (S) protein and activation of the $S$ protein by proteolytic priming, respectively. Epithelial cells are the major target of SARS-CoV-2 infection and several studies have highlighted cross-talk between the epithelial cells and basophils (17-19). Therefore, we surmised that epithelial cells infected with SARS-CoV-2 could affect activation of basophils. Though A549 lung epithelial cells have been reported to induce activation of human basophils (18), they lack both ACE2 and TMPRSS2 receptors (20). On the other hand, human colorectal adenocarcinoma cells (Caco-2 cells) were reported to express both ACE2 and TMPRSS2 receptors and support SARS-CoV-2 replication (20). Virus titration experiments have confirmed that Caco-2 are permissive to SARS-CoV-2 infection (Figure 3A). However, SARS-CoV-2infected Caco-2 cells did not alter either phenotype of basophils (Figure 3B) or cytokines secreted (Figure 3C).

\section{SARS-CoV-2 Does Not Induce PD-L1 on the Basophils}

Immuno-phenotyping studies have revealed that programmed death receptor ligand 1 (PD-L1, CD274, B7-H1; family of B7 costimulatory molecule) is dysregulated on monocytes, neutrophils, and T cells in COVID-19 patients (21). In addition, an enhanced expression of PD-L1 was also observed on the peripheral blood basophils of severe COVID-19 patients $(11,22-24)$, though this observation was not confirmed by another report (11). Therefore, we investigated the repercussion of SARS-CoV-2 infection on the expression of PD-L1 on the basophils at $24 \mathrm{~h}$. We found that both resting as well as SARS-CoV-2-infected basophils lacked the expression of PD-L1 (Figure 4A). Similar results were also obtained with IL-3primed basophils (Figure 4B) and basophils co-cultured with virus-infected Caco-2 (Figure 4C). Our control experiments have indicated that the expression of PD-L1 on the basophils did not differ at 24 and $48 \mathrm{~h}$. These data together suggest that SARS-CoV-2 does not induce PD-L1 on the basophils and altered expression of this molecule observed on the basophils from COVID-19 patients was possibly due to the inflammatory cytokine responses.

\section{DISCUSSION}

Various studies have confirmed the dysregulation of immune system, particularly cells of the innate immune system and cytokine storm in severe COVID-19 patients (25). Systemslevel immuno-monitoring of adult COVID-19 patients by mass-cytometry revealed that polymorphonuclear granulocytes 
A
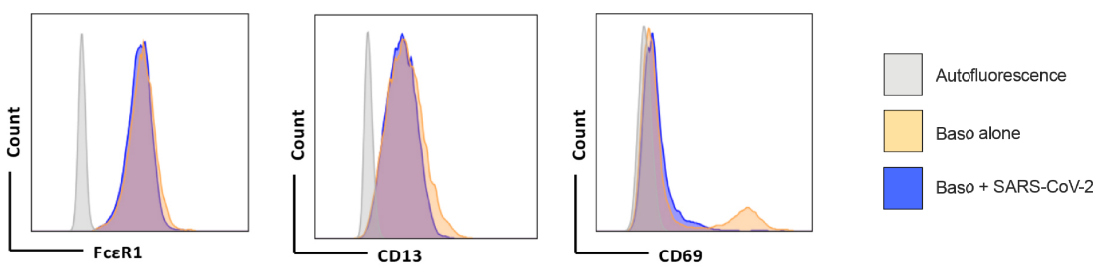

B
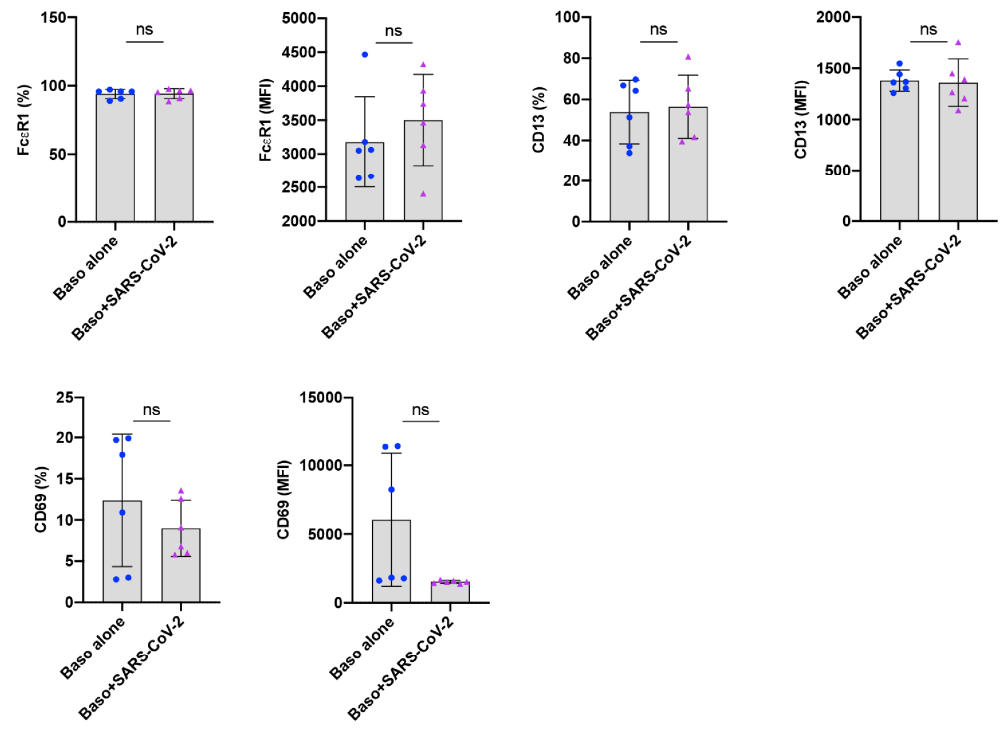

C
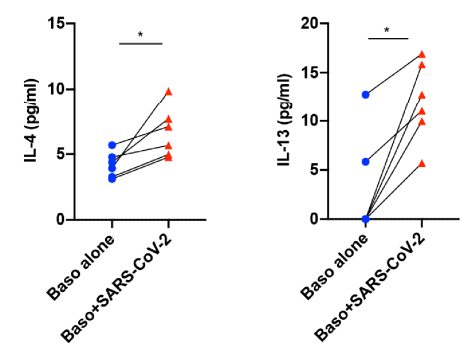

FIGURE 1 | Resting human basophils undergo limited activation upon stimulation with SARS-CoV-2. Basophils $\left(0.1 \times 10^{6}\right.$ cells/100 $\mu$ l) isolated from PBMCs of healthy donors were cultured with or without SARS-CoV-2 at a MOI of 1. Cell phenotype was evaluated by flow cytometry after 24 h. (A) Representative histogram overlays displaying the expression pattern of FCeR1, CD13 and CD69 on basophils under various experimental conditions. (B) Expression of FCeR1, CD13 and CD69 on basophils (\% positive cells and median fluorescence intensities (MFI), mean \pm SD; $n=6$ independent donors). (C) The amount (pg/ml) of secreted IL-4 and IL-13 in the cell-free supernatant from the above experiments (mean $\pm S D, n=6$ independent donors). ns, not significant, ${ }^{*} P<0.05$, paired Wilcoxon test.

(neutrophils, eosinophils, and basophils) are differentially regulated in the circulation during infection (2). Both absolute count and relative frequencies of basophils are decreased in moderate and severe COVID-19 patients $(11,26)$. However, in contrast to neutrophils, basophils are increased from acute to recovery phase though another cohort reported no difference in the basophil count in COVID-19 patients during acute phase as compared to healthy donors (27). An activated phenotype of basophils was also documented in COVID-19 patients (11) though the underlying mechanisms are not known. In view of activation of complement pathway in COVID-19 patients (2830) and that human basophils express C5aR and C3aR (31), indirect activation of basophils in COVID-19 patients through complement components cannot be ruled out. However, direct or indirect interaction of basophils with SARS-CoV-2 has not been investigated yet, despite their vital role in the pulmonary pathologies and regulation of immune responses. The low frequency of basophils ( 0.2 to $0.5 \%$ of leukocytes) in the circulation is one of the main limitations for researchers to study the basophils.

Direct capture of human immunodeficiency virus (HIV)-1 by basophils has been described (32), though the identity of pattern recognition receptor (PRR) that mediates virus capture is not clear (33). Human basophils produce histamine when cells are 
A

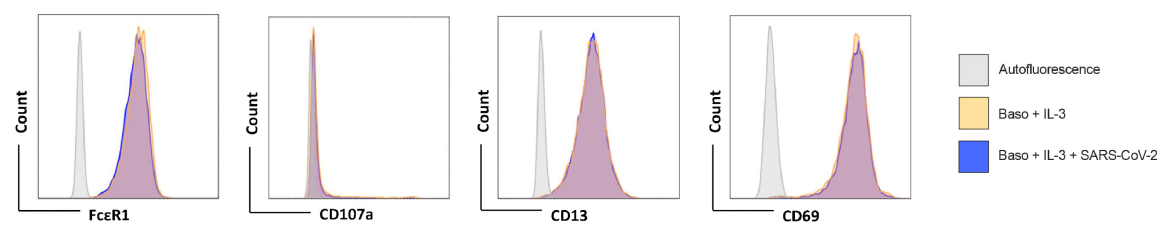

B
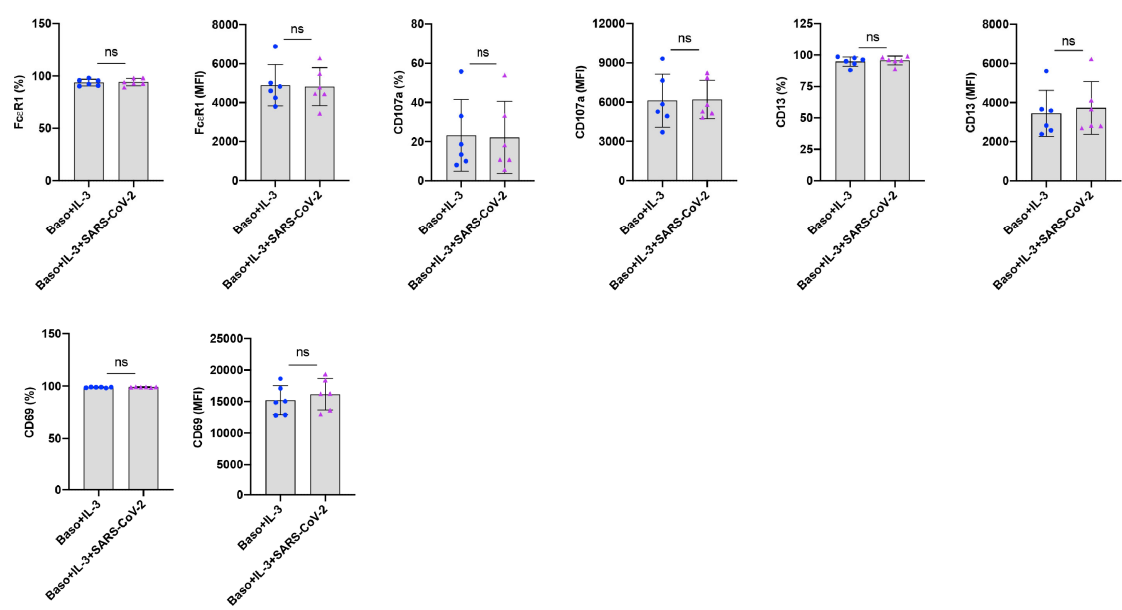

C

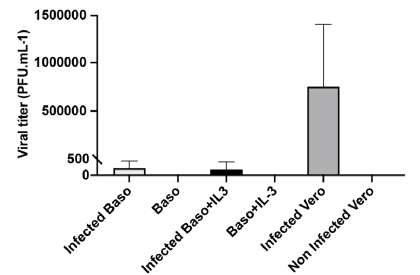

D

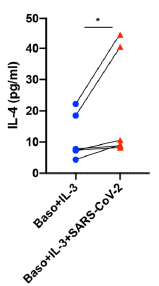

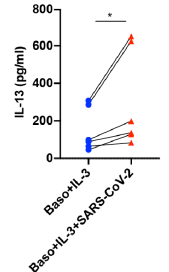

FIGURE 2 | SARS-CoV-2 enhances cytokines in IL-3-primed basophils. Basophils $\left(0.1 \times 10^{6} \mathrm{cells} / 100 \mu \mathrm{ll}\right)$ from the healthy donors were primed with IL-3 (20 ng/ml) along with infection with SARS-CoV-2 at a MOI of 1 . Non-infected basophils were used as a control. Cell phenotype was evaluated by flow cytometry after $24 \mathrm{~h}$. (A) Representative histogram overlays displaying the expression pattern of FCeR1, CD107a, CD13 and CD69 on basophils under different experimental conditions. (B) Expression of FceR1, CD107a, CD13 and CD69 on the basophils (\% positive cells and median fluorescence intensities (MFI), mean \pm SD; $n=6$ independent donors). (C) Basophils are not permissive to SARS-CoV-2 replication. Either resting basophils $\left(0.1 \times 10^{6} \mathrm{cell} / \mathrm{s} /\right.$ well/96 well plate) or IL-3-primed basophils were infected with SARS-CoV-2 (mean \pm SD, $n=6$ independent donors). Viral titers were evaluated after $24 \mathrm{~h}$ post-infection. Infected and non-infected Vero E6 cells were used as controls for the infection ( $n=3)$. (D) The amount $(\mathrm{pg} / \mathrm{ml})$ of secreted IL-4 and IL-13 in the cell-free supernatant from the above experiments (mean \pm SD, $n=6$ independent donors). $n s$, not significant, ${ }^{\star} P<0.05$, paired Wilcoxon test.

incubated with paramyxoviruses, thus indicating that basophils have a capacity to respond to virus stimuli (34). In addition, human basophilic cell line (KU812) has been demonstrated to be permissive to rhinovirus infection in vitro (35). In view of these observations and the role of basophils in various respiratory pathologies, we investigated the cross-talk between SARS-CoV-2 and basophils. Our data suggest that SARS-CoV-2 could induce partial activation of basophils leading to the secretion of cytokines, IL-4 and IL-13, both in resting and IL-3-primed basophils. The effect of SARS-CoV-2 on IL-13 induction was particularly remarkable in IL-3 primed condition. The mechanism by which SARS-CoV-2 induces basophil activation is the subject of future investigation.
Previous data have shown inability of SARS-CoV-2 to replicate in various immune cells (36). Also, proteomic and genomic data clearly highlighted the absence of ACE2 receptor on the basophils (37). Therefore, we believe that SARS-CoV-2 could induce basophil activation by signaling through PRR in coordination with cytokines like IL-3. Activated T cells are the major source of IL-3 $(14,38,39)$ and flow cytometric data showed that IL-3 in COVID-19 patients is contributed mainly by $\mathrm{CD}^{+} \mathrm{T}$ cells (40). Of note, low levels of IL-3 in the circulation of COVID-19 patients is associated with enhanced severity of the disease and mortality (40). Mechanistically, it was proposed that IL-3 enhances the recruitment of plasmacytoid dendritic cells into the airways and hence boosts the anti-viral innate immunity. 
A

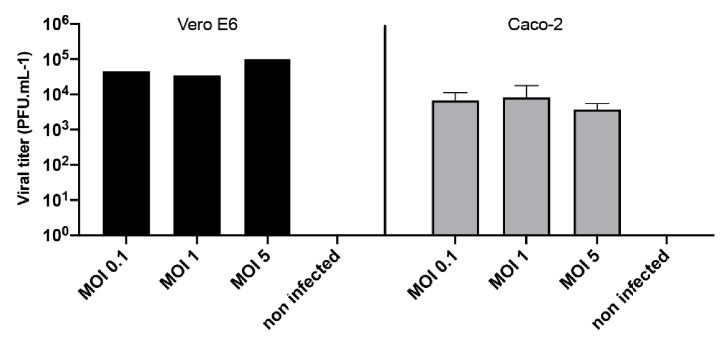

B
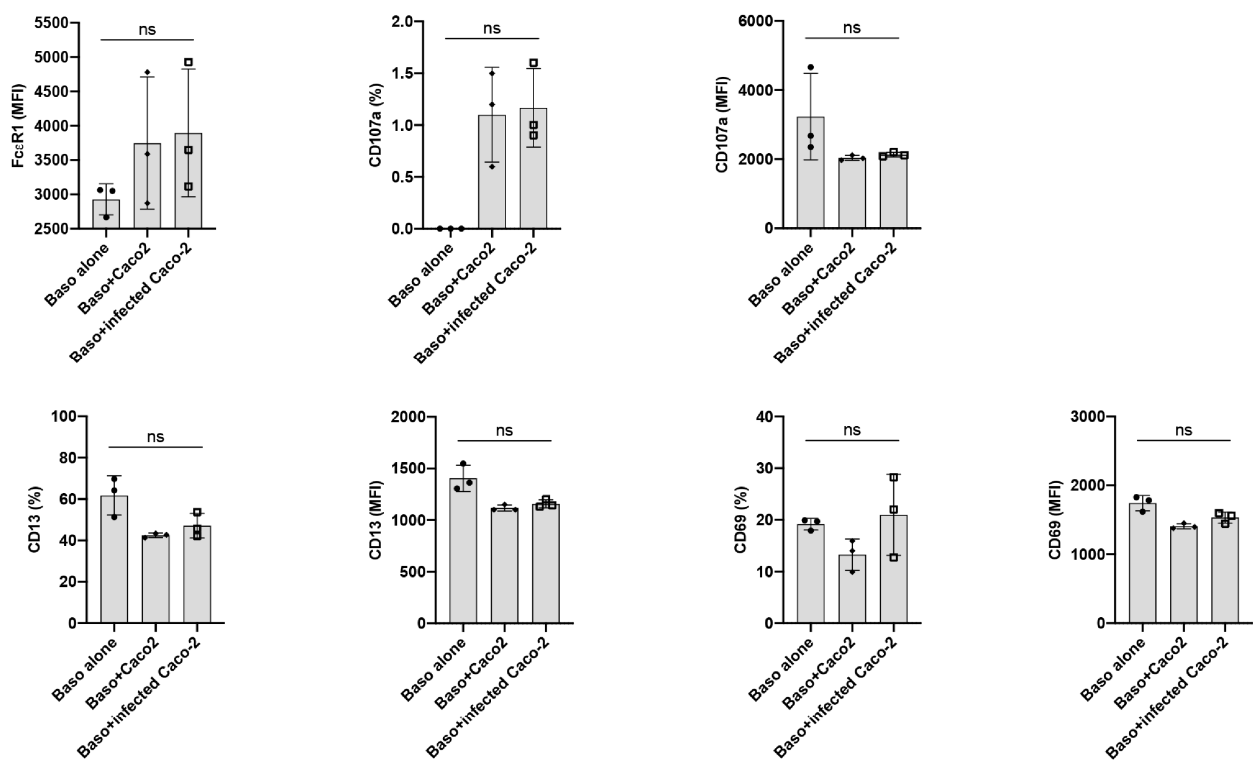

C
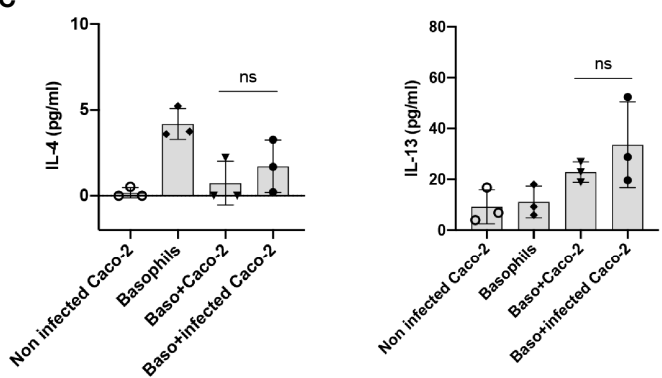

FIGURE 3 | Lack of basophil activation by SARS-CoV-2 infected epithelial cells. (A) Caco-2 cells permit SARS-CoV-2 replication. Caco-2 cells ( $1.5 \times 10^{5}$ cells per well/24 well plate) in duplicates were infected with SARS-CoV-2 at the MOI of $0.1,1$ and 5 . Viral titers were evaluated after $72 \mathrm{~h}$ post-infection. Data were presented as mean \pm SD. Infection of Vero E6 cells with SARS-CoV-2 was used as a control. (B, C) Basophils were cultured as follows: basophils alone $\left(0.1 \times 10^{6}\right.$ cells/100 $\mu$ l), basophils $\left(0.1 \times 10^{6}\right.$ cells $\left./ 100 \mu l\right)+$ Caco-2 $\left(5 \times 10^{4}\right.$ cells/100 $\mu$ l), and basophils + Caco-2 infected with SARS-CoV-2. Cell phenotype was evaluated by flow cytometry after 24 h. (B) Expression of FceR1, CD107a, CD13, CD69 on basophils (\% positive cells and/or median fluorescence intensities (MFI), mean \pm SD; $n=3$ independent donors). (C) The amount (pg/ml) of secreted IL-4 and IL-13 in the cell-free supernatant from the above experiments (mean \pm SD, $n=3$ independent donors). ns, not significant, one-way ANOVA Friedman test with Dunn's multiple comparisons post-test.

Our data imply that IL-3 also primes basophils to secrete higher amounts of cytokines IL-13 and IL-4 in response to virus stimulation that might help in reducing the inflammation and also to promote antibody responses to the SARS-CoV-2.

Interaction between the checkpoint molecules programmed cell death protein PD-1 and PD-L1 plays a key role in maintaining immune tolerance (41-43). However, immune exhaustion by signaling through checkpoint molecules could prevent effective clearance of the pathogens leading to exacerbated immune responses $(44,45)$. PD-L1 and PD-1 interaction also supports regulatory $\mathrm{T}$ cell responses (46-50). Of note, PD-L1 expression was significantly higher in a group of severe COVID-19 patients as compared to milder patients and was positively correlated with the WHO and Sequential Organ 


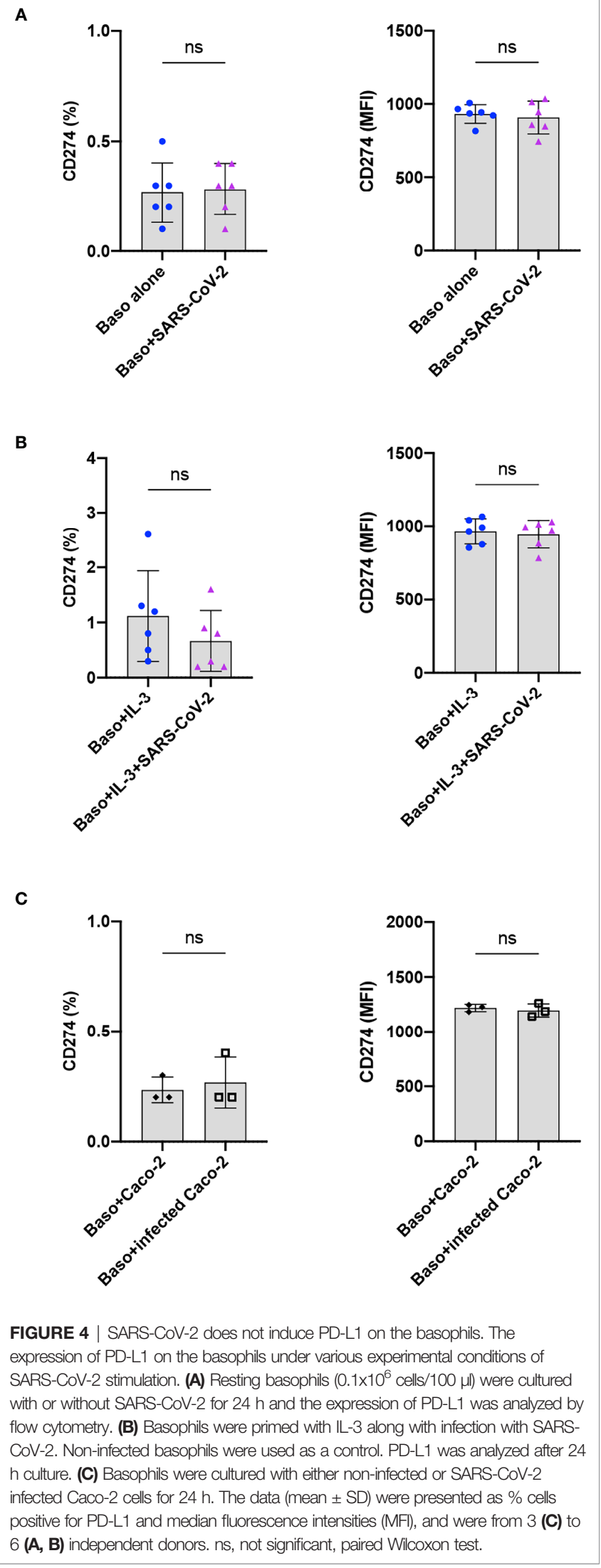

Failure Assessment (SOFA) clinical scores (22). It is likely that the induced expression of PD-L1 in severe COVID-19 patients might be responsible for the $\mathrm{T}$ cell exhaustion. The trigger that induces PD-L1 on the basophils from COVID-19 patients is not known. Our data however suggest that SARS-CoV-2 infection does not induce PD-L1 on the basophils (51). However, PD-L1 on basophils may not influence the effector $\mathrm{CD}^{+}{ }^{+} \mathrm{T}$ cell responses as basophils lack the features of antigen presenting cells (52-56). In view of these facts, the significance of basophilPD-L1 in the pathogenesis of COVID-19 remains unclear.

SARS-CoV-2 entry is facilitated by the presence of ACE2 and TMPRSS2 receptors on the host cells. These receptors are highly expressed by epithelial cells that are present in the lungs and gastrointestinal tract. Several innate stimuli including epithelial derived inflammatory cytokines (IL-33, IL-18, Thymic stromal lymphopoietin, and GM-CSF), growth factors (IL-3, IL-7, TGF$\beta$, and VEGF) activate the mouse basophils (57). Also, airway epithelial cell line A549 has been reported to induce activation of human basophils (18). Whether other epithelial cells also display similar capacity to induce basophil activation is not known. Our results however suggest that Caco-2 cells lack the ability to induce basophil activation. Primary lung epithelial cells need to be used to examine the cross-talk between SARS-CoV-2-infected airway epithelial cells and basophils, and is the limitation of our study.

\section{DATA AVAILABILITY STATEMENT}

The original contributions presented in the study are included in the article/supplementary material. Further inquiries can be directed to the corresponding author.

\section{ETHICS STATEMENT}

EFS-INSERM permission (18/EFS/041) was obtained for the purchase of healthy donors buffy coats used in the study.

\section{AUTHOR CONTRIBUTIONS}

JB conceptualized, designed and coordinated the study, contributed to the interpretation of the results and wrote the paper. SB, CC, LL, and MJM performed the experiments and participated in the data interpretation and wrote the first draft of the paper. AS coordinated the study along with JB. All authors read and approved the final submitted version of the article.

\section{FUNDING}

Agence Nationale de la Recherche, France under the call "Flash COVID-19" (ANR-20-COVI-0093-COVIMUNE) and ANR-19CE17-0021 (BASIN). 


\section{ACKNOWLEDGMENTS}

We thank the staff of core facilities [Centre d'Histologie, d'Imagerie et de Cytométrie (CHIC)] at Centre de Recherche des Cordeliers for the help. We would like to thank the National

\section{REFERENCES}

1. Who Coronavirus (Covid-19) Dashboard. Geneva, Switzerland: WHO (2021). Available at: https://covid19.who.int/.

2. Rodriguez L, Pekkarinen PT, Lakshmikanth T, Tan Z, Consiglio CR, Pou C, et al. Systems-Level Immunomonitoring From Acute to Recovery Phase of Severe Covid-19. Cell Rep Med (2020) 1:100078. doi: 10.1016/j.xcrm. 2020.100078

3. Koutsakos M, Rowntree LC, Hensen L, Chua BY, van de Sandt CE, Habel JR, et al. Integrated Immune Dynamics Define Correlates of Covid-19 Severity and Antibody Responses. Cell Rep Med (2021) 2:100208. doi: 10.1016/ j.xcrm.2021.100208

4. Ogbe A, Kronsteiner B, Skelly DT, Pace M, Brown A, Adland E, et al. T Cell Assays Differentiate Clinical and Subclinical Sars-Cov-2 Infections From Cross-Reactive Antiviral Responses. Nat Commun (2021) 12:2055. doi: 10.1038/s41467-021-21856-3

5. Gaebler C, Wang Z, Lorenzi JCC, Muecksch F, Finkin S, Tokuyama M, et al. Evolution of Antibody Immunity to Sars-Cov-2. Nature (2021) 591:639-44. doi: 10.1038/s41586-021-03207-w

6. Trombetta AC, Farias GB, Gomes AMC, Godinho-Santos A, Rosmaninho P, Conceicao CM, et al. Severe Covid-19 Recovery Is Associated With Timely Acquisition of a Myeloid Cell Immune-Regulatory Phenotype. Front Immunol (2021) 12:691725. doi: 10.3389/fimmu.2021.691725

7. Bost P, De Sanctis F, Cane S, Ugel S, Donadello K, Castellucci M, et al. Deciphering the State of Immune Silence in Fatal Covid-19 Patients. Nat Commun (2021) 12:1428. doi: 10.1038/s41467-021-21702-6

8. Voehringer D. Protective and Pathological Roles of Mast Cells and Basophils. Nat Rev Immunol (2013) 13:362-75. doi: 10.1038/nri3427

9. Karasuyama H, Miyake K, Yoshikawa S, Yamanishi Y. Multifaceted Roles of Basophils in Health and Disease. J Allergy Clin Immunol (2018) 142:370-80. doi: 10.1016/j.jaci.2017.10.042

10. Karasuyama H, Shibata S, Yoshikawa S, Miyake K. Basophils, a Neglected Minority in the Immune System, Have Come Into the Limelight at Last. Int Immunol (2021) 33:809-13. doi: 10.1093/intimm/dxab021

11. Lourda M, Dzidic M, Hertwig L, Bergsten H, Palma Medina LM, Sinha I, et al. High-Dimensional Profiling Reveals Phenotypic Heterogeneity and DiseaseSpecific Alterations of Granulocytes in Covid-19. Proc Natl Acad Sci USA (2021) 118:e2109123118. doi: 10.1073/pnas.2109123118

12. Voehringer D. Basophil Modulation by Cytokine Instruction. Eur J Immunol (2012) 42:2544-50. doi: 10.1002/eji.201142318

13. Yoshimura C, Yamaguchi $M$, Iikura M, Izumi S, Kudo K, Nagase $H$, et al. Activation Markers of Human Basophils: Cd69 Expression Is Strongly and Preferentially Induced by Il-3. J Allergy Clin Immunol (2002) 109:817-23. doi: $10.1067 /$ mai.2002.123532

14. Sharma M, Das M, Stephen-Victor E, Galeotti C, Karnam A, Maddur MS, et al. Regulatory T Cells Induce Activation Rather Than Suppression of Human Basophils. Sci Immunol (2018) 3:eaan0829. doi: 10.1126/sciimmunol.aan0829

15. Galeotti C, Stephen-Victor E, Karnam A, Das M, Gilardin L, Maddur MS, et al. Intravenous Immunoglobulin Induces Il-4 in Human Basophils by Signaling Through Surface-Bound Ige. J Allergy Clin Immunol (2019) 144:524-35 e8. doi: 10.1016/j.jaci.2018.10.064

16. Ochensberger B, Daepp GC, Rihs S, Dahinden CA. Human Blood Basophils Produce Interleukin-13 in Response to Ige- Receptor-Dependent and -Independent Activation. Blood (1996) 88:3028-37. doi: 10.1182/ blood.V88.8.3028.bloodjournal8883028

17. Motomura Y, Morita H, Moro K, Nakae S, Artis D, Endo TA, et al. BasophilDerived Interleukin-4 Controls the Function of Natural Helper Cells, A Member of Ilc2s, in Lung Inflammation. Immunity (2014) 40:758-71. doi: 10.1016/j.immuni.2014.04.013
Reference Centre for Respiratory Viruses hosted by Institut Pasteur (Paris, France) and headed by Dr. Sylvie van der Werf for providing the virus strain. The human sample was isolated and provided by Drs. Xavier Lescure, Yazdan Yazdanpanah from the Bichat Hospital, Paris.

18. Schroeder JT, Bieneman AP. Activation of Human Basophils by A549 Lung Epithelial Cells Reveals a Novel Ige-Dependent Response Independent of Allergen. J Immunol (2017) 199:855-65. doi: 10.4049/jimmunol.1700055

19. Roan F, Obata-Ninomiya K, Ziegler SF. Epithelial Cell-Derived Cytokines: More Than Just Signaling the Alarm. J Clin Invest (2019) 129:1441-51. doi: 10.1172/JCI124606

20. Wing PAC, Keeley TP, Zhuang X, Lee JY, Prange-Barczynska M, Tsukuda S, et al. Hypoxic and Pharmacological Activation of Hif Inhibits Sars-Cov-2 Infection of Lung Epithelial Cells. Cell Rep (2021) 35:109020. doi: 10.1016/ j.celrep.2021.109020

21. Sabbatino F, Conti V, Franci G, Sellitto C, Manzo V, Pagliano P, et al. Pd-L1 Dysregulation in Covid-19 Patients. Front Immunol (2021) 12:695242. doi: 10.3389 /fimmu.2021.695242

22. Vitte J, Diallo AB, Boumaza A, Lopez A, Michel M, Allardet-Servent J, et al. A Granulocytic Signature Identifies Covid-19 and Its Severity. J Infect Dis (2020) 222:1985-96. doi: 10.1093/infdis/jiaa591

23. Vitte J, Diallo AB, Boumaza A, Lopez A, Michel M, Allardet-Servent J, et al. Reply to Chen and Vitetta. J Infect Dis (2021) 223:1660-2. doi: 10.1093/infdis/ jiab062

24. Chen J, Vitetta L. Increased Pd-L1 Expression May Be Associated With the Cytokine Storm and Cd8+ T-Cell Exhaustion in Severe Covid-19. J Infect Dis (2021) 223:1659-60. doi: 10.1093/infdis/jiab061

25. Bonam SR, Kaveri SV, Sakuntabhai A, Gilardin L, Bayry J. Adjunct Immunotherapies for the Management of Severely Ill Covid-19 Patients. Cell Rep Med (2020) 1:100016. doi: 10.1016/j.xcrm.2020.100016

26. Laing AG, Lorenc A, Del Molino Del Barrio I, Das A, Fish M, Monin L, et al. A Dynamic Covid-19 Immune Signature Includes Associations With Poor Prognosis. Nat Med (2020) 26:1623-35. doi: 10.1038/s41591-020-1038-6

27. Mathew D, Giles JR, Baxter AE, Oldridge DA, Greenplate AR, Wu JE, et al. Deep Immune Profiling of Covid-19 Patients Reveals Distinct Immunotypes With Therapeutic Implications. Science (2020) 369:eabc8511. doi: 10.1126/ science.abc8511

28. Afzali B, Noris M, Lambrecht BN, Kemper C. The State of Complement in Covid-19. Nat Rev Immunol (2022) 22:77-84. doi: 10.1038/s41577-02100665-1

29. Senent Y, Inogés S, López-Díaz de Cerio A, Blanco A, Campo A, CarmonaTorre F, et al. Persistence of High Levels of Serum Complement C5a in Severe Covid-19 Cases After Hospital Discharge. Front Immunol (2021) 12:767376. doi: 10.3389/fimmu.2021.767376

30. Cyprian FS, Suleman M, Abdelhafez I, Doudin A, Masud Danjuma IM, Mir FA, et al. Complement C5a and Clinical Markers as Predictors of Covid-19 Disease Severity and Mortality in a Multi-Ethnic Population. Front Immunol (2021) 12:707159. doi: 10.3389/fimmu.2021.707159

31. Zwirner J, Gotze O, Begemann G, Kapp A, Kirchhoff K, Werfel T. Evaluation of C3a Receptor Expression on Human Leucocytes by the Use of Nove Monoclonal Antibodies. Immunology (1999) 97:166-72. doi: 10.1046/j.13652567.1999.00764.x

32. Jiang AP, Jiang JF, Guo MG, Jin YM, Li YY, Wang JH. Human BloodCirculating Basophils Capture Hiv-1 and Mediate Viral Trans-Infection of Cd4+ T Cells. J Virol (2015) 89:8050-62. doi: 10.1128/JVI.01021-15

33. Das M, Galeotti C, Stephen-Victor E, Karnam A, Kaveri SV, Bayry J. Human Basophils May Not Undergo Modulation by Dc-Sign and Mannose ReceptorTargeting Immunotherapies Due to Absence of Receptors. J Allergy Clin Immunol (2017) 139:1403-4 e1. doi: 10.1016/j.jaci.2016.09.062

34. Sanchezlegrand F, Smith T. Interaction of Paramyxoviruses With Human Basophils and Their Effect on Histamine Release. J Allergy Clin Immunol (1989) 84:538-46. doi: 10.1016/0091-6749(89)90368-0

35. Hosoda M, Yamaya M, Suzuki T, Yamada N, Kamanaka M, Sekizawa K, et al. Effects of Rhinovirus Infection on Histamine and Cytokine Production by Cell 
Lines From Human Mast Cells and Basophils. J Immunol (2002) 169:1482-91. doi: 10.4049/jimmunol.169.3.1482

36. Jiang M, Kolehmainen P, Kakkola L, Maljanen S, Melen K, Smura T, et al. Sars-Cov-2 Isolates Show Impaired Replication in Human Immune Cells But Differential Ability to Replicate and Induce Innate Immunity in Lung Epithelial Cells. Microbiol Spectr (2021) 9:e0077421. doi: 10.1128/ Spectrum.00774-21

37. Wang Y, Wang Y, Luo W, Huang L, Xiao J, Li F, et al. A Comprehensive Investigation of the Mrna and Protein Level of Ace2, the Putative Receptor of Sars-Cov-2, in Human Tissues and Blood Cells. Int J Med Sci (2020) 17:152231. doi: 10.7150/ijms. 46695

38. Sullivan BM, Liang HE, Bando JK, Wu D, Cheng LE, McKerrow JK, et al. Genetic Analysis of Basophil Function in Vivo. Nat Immunol (2011) 12:52735. doi: 10.1038/ni.2036

39. Leyva-Castillo JM, Hener P, Michea P, Karasuyama H, Chan S, Soumelis V, et al. Skin Thymic Stromal Lymphopoietin Initiates Th2 Responses Through an Orchestrated Immune Cascade. Nat Commun (2013) 4:2847. doi: 10.1038/ ncomms 3847

40. Benard A, Jacobsen A, Brunner M, Krautz C, Klosch B, Swierzy I, et al. Interleukin-3 Is a Predictive Marker for Severity and Outcome During SarsCov-2 Infections. Nat Commun (2021) 12:1112. doi: 10.1038/s41467-021-21310-4

41. Francisco LM, Sage PT, Sharpe AH. The Pd-1 Pathway in Tolerance and Autoimmunity. Immunol Rev (2010) 236:219-42. doi: 10.1111/j.1600065X.2010.00923.X

42. Tumeh PC, Harview CL, Yearley JH, Shintaku IP, Taylor EJ, Robert L, et al. Pd-1 Blockade Induces Responses by Inhibiting Adaptive Immune Resistance. Nature (2014) 515:568-71. doi: 10.1038/nature13954

43. Jubel JM, Barbati ZR, Burger C, Wirtz DC, Schildberg FA. The Role of Pd-1 in Acute and Chronic Infection. Front Immunol (2020) 11:487. doi: 10.3389/ fimmu.2020.00487

44. Zinselmeyer BH, Heydari S, Sacristan C, Nayak D, Cammer M, Herz J, et al. Pd-1 Promotes Immune Exhaustion by Inducing Antiviral T Cell Motility Paralysis. J Exp Med (2013) 210:757-74. doi: 10.1084/jem.20121416

45. Klein S, Ghersi D, Manns MP, Prinz I, Cornberg M, Kraft ARM. Pd-L1 Checkpoint Inhibition Narrows the Antigen-Specific T Cell Receptor Repertoire in Chronic Lymphocytic Choriomeningitis Virus Infection. J Virol (2020) 94:e00795-20. doi: 10.1128/JVI.00795-20

46. Wang L, Pino-Lagos K, de Vries VC, Guleria I, Sayegh MH, Noelle RJ. Programmed Death 1 Ligand Signaling Regulates the Generation of Adaptive Foxp3+Cd4+ Regulatory T Cells. Proc Natl Acad USA (2008) 105:9331-6. doi: $10.1073 /$ pnas. 0710441105

47. Amarnath S, Mangus CW, Wang JC, Wei F, He A, Kapoor V, et al. The Pdl1Pd1 Axis Converts Human Th1 Cells Into Regulatory T Cells. Sci Transl Med (2011) 3:111ra20. doi: 10.1126/scitranslmed.3003130

48. Stephen-Victor E, Karnam A, Fontaine T, Beauvais A, Das M, Hegde P, et al. Aspergillus Fumigatus Cell Wall Alpha-(1,3)-Glucan Stimulates Regulatory T-Cell Polarization by Inducing Pd-L1 Expression on Human Dendritic Cells. J Infect Dis (2017) 216:1281-94. doi: 10.1093/infdis/jix469

49. Fanelli G, Romano M, Nova-Lamperti E, Werner Sunderland M, Nerviani A, Scotta C, et al. Pd-L1 Signaling on Human Memory Cd4+ T Cells Induces a
Regulatory Phenotype. PloS Biol (2021) 19:e3001199. doi: 10.1371/ journal.pbio.3001199

50. Karnam A, Bonam SR, Rambabu N, Wong SSW, Aimanianda V, Bayry J. Wnt-Beta-Catenin Signaling in Human Dendritic Cells Mediates Regulatory T-Cell Responses to Fungi Via the Pd-L1 Pathway. mBio (2021) 0:e0282421. doi: $10.1128 / \mathrm{mBio} .02824-21$

51. Lee SJ, Jang BC, Lee SW, Yang YI, Suh SI, Park YM, et al. Interferon Regulatory Factor-1 Is Prerequisite to the Constitutive Expression and IfnGamma-Induced Upregulation of B7-H1 (Cd274). FEBS Lett (2006) 580:75562. doi: 10.1016/j.febslet.2005.12.093

52. Eckl-Dorna J, Ellinger A, Blatt K, Ghanim V, Steiner I, Pavelka M, et al. Basophils Are Not the Key Antigen-Presenting Cells in Allergic Patients. Allergy (2012) 67:601-8. doi: 10.1111/j.1398-9995.2012.02792.x

53. Kitzmuller C, Nagl B, Deifl S, Walterskirchen C, Jahn-Schmid B, Zlabinger GJ, et al. Human Blood Basophils Do Not Act as Antigen-Presenting Cells for the Major Birch Pollen Allergen Bet V 1. Allergy (2012) 67:593-600. doi: 10.1111/ j.1398-9995.2011.02764.x

54. Sharma M, Hegde P, Aimanianda V, Beau R, Maddur MS, Sénéchal H, et al. Circulating Human Basophils Lack the Features of Professional Antigen Presenting Cells. Sci Rep (2013) 3:1188. doi: 10.1038/srep01188

55. Sharma M, Stephen-Victor E, Poncet P, Kaveri SV, Bayry J. Basophils Are Inept at Promoting Human Th17 Responses. Hum Immunol (2015) 76:17680. doi: 10.1016/j.humimm.2014.12.015

56. Emmanuel S-V, Mrinmoy D, Meenu S, Caroline G, Hélène F-T, Boualem S, et al. Demystification of Enigma on Antigen-Presenting Cell Features of Human Basophils: Data From Secondary Lymphoid Organs. Haematologica (2017) 102:e233-e7. doi: 10.3324/haematol.2016.163451

57. Pellefigues C, Mehta P, Chappell S, Yumnam B, Old S, Camberis M, et al. Diverse Innate Stimuli Activate Basophils Through Pathways Involving Syk and Ikappab Kinases. Proc Natl Acad Sci USA (2021) 118:e2019524118. doi: $10.1073 /$ pnas.2019524118

Conflict of Interest: The authors declare that the research was conducted in the absence of any commercial or financial relationships that could be construed as a potential conflict of interest.

Publisher's Note: All claims expressed in this article are solely those of the authors and do not necessarily represent those of their affiliated organizations, or those of the publisher, the editors and the reviewers. Any product that may be evaluated in this article, or claim that may be made by its manufacturer, is not guaranteed or endorsed by the publisher.

Copyright (c) 2022 Bonam, Chauvin, Levillayer, Mathew, Sakuntabhai and Bayry. This is an open-access article distributed under the terms of the Creative Commons Attribution License (CC BY). The use, distribution or reproduction in other forums is permitted, provided the original author(s) and the copyright owner(s) are credited and that the original publication in this journal is cited, in accordance with accepted academic practice. No use, distribution or reproduction is permitted which does not comply with these terms. 